\title{
Editorial
}

Journal of Innate

Immunity
J Innate Immun 2015;7:555-556

DOI: $10.1159 / 000431055$

Published online: September 8, 2015

\section{The Neutrophil: A Beautiful Beast or a Beastly Beauty?}

Neutrophils are crucial to keeping us in a healthy state, but they also play important roles in the pathophysiology of a broad spectrum of diseases [1]. Early on, they were regarded as quite primitive cells, simply executing cytotoxic functions. It has become evident, however, that they are highly sophisticated and can perform complex functions in many inflammatory contexts. Neutrophils originate from stem cells in the bone marrow where growth factors induce sequential expression of genes, resulting in a distinct phenotype, not least characterized by its different sets of cytoplasmic granule containing preformed host defense proteins ready to be released at sites of inflammation [1]. Being transported in the bloodstream, specific adhesion molecules expressed by endothelial cells and chemotactic gradients are important for neutrophil recruitment and activation [2-5].

ELR-positive CXC chemokines, including IL-8/ CXCL8, are important during this process. Interestingly, there are two receptors for this group of ligands with varying affinities [6-8]. CXCL1 mediates neutrophil recruitment by binding and activating CXCR2, and inhibition of this receptor shows that dysregulation of CXCL1/ CXCR2 function is correlated with the severity of disease [9]. However, the mechanisms that turn the beneficial CXCL1-mediated neutrophil functions into a destructive phenotype are not known. In this issue, Sawant et al. [9] present highly interesting data showing that CXCL1 monomer-dimer distribution and receptor interactions are highly coupled and regulate neutrophil trafficking, and that injury in the context of disease is a consequence of inappropriate CXCR2 activation at the target tissue [10].

The classic view is that neutrophils are important in bacterial killing [11]. However, they can also recognize damage-associated molecular patterns (DAMPs) during tissue-damage and participate in viral host defense [12, 13]. Another important function is the formation of neutrophil extracellular traps (NETs), formed during an active cellular process where the neutrophil releases its DNA to the extracellular environment $[14,15]$. Finally, resolution of neutrophil inflammation has to be tightly regulated to avoid accumulation of these cells, as is exemplified by the prolonged and excessive inflammation in cystic fibrosis [16-18].

The rapidly increasing knowledge regarding the immunobiology of this fascinating and important cell should attract the attention of a broad readership interested in innate immunity.

Heiko Herwald, Lund Arne Egesten, Lund 


\section{References}

1 Nauseef WM, Borregaard N: Neutrophils at work. Nat Immunol 2014;15:602-611.

2 Daniel AE, van Buul JD: Endothelial junction regulation: a prerequisite for leukocytes crossing the vessel wall. J Innate Immun 2013; 5:324-335.

3 Grommes J, Drechsler M, Soehnlein O: CCR5 and FPR1 mediate neutrophil recruitment in endotoxin-induced lung injury. J Innate Immun 2014;6:111-116.

4 Rossaint J, Zarbock A: Tissue-specific neutrophil recruitment into the lung, liver, and kidney. J Innate Immun 2013;5:348-357.

5 Herter JM, Rossaint J, Spieker T, Zarbock A: Adhesion molecules involved in neutrophil recruitment during sepsis-induced acute kidney injury. J Innate Immun 2014;6:597-606.

6 Murphy PM, Tiffany HL: Cloning of complementary DNA encoding a functional human interleukin-8 receptor. Science 1991;253: 1280-1283.

7 Holmes WE, Lee J, Kuang WJ, Rice GC, Wood WI: Structure and functional expression of a human interleukin-8 receptor. Science 1991;253:1278-1280.
8 Moser B, Schumacher C, von Tscharner V, Clark-Lewis I, Baggiolini M: Neutrophil-activating peptide 2 and gro/melanoma growthstimulatory activity interact with neutrophilactivating peptide 1/interleukin 8 receptors on human neutrophils. J Biol Chem 1991;266: 10666-10671.

9 Sawant KV, Xu R, Cox R, Hawkins H, Sbrana E, Kolli D, Garofalo RP, Rajarathnam K: Chemokine CXCL1-mediated neutrophil trafficking in the lung: role of CXCR2 activation. J Innate Immun 2015;7:647-658.

10 Nagarkar DR, Wang Q, Shim J, Zhao Y, Tsai WC, Lukacs NW, Sajjan U, Hershenson MB: CXCR2 is required for neutrophilic airway inflammation and hyperresponsiveness in a mouse model of human rhinovirus infection. J Immunol 2009;183:6698-6707.

11 Lu T, Porter AR, Kennedy AD, Kobayashi SD DeLeo FR: Phagocytosis and killing of Staphylococcus aureus by human neutrophils. J Innate Immun 2014;6:639-649.

12 Pittman K, Kubes P: Damage-associated molecular patterns control neutrophil recruitment. J Innate Immun 2013;5:315-323.

13 Casulli S, Elbim C: Interactions between human immunodeficiency virus type 1 and polymorphonuclear neutrophils. J Innate Immun 2014;6:13-20.
14 Brinkmann V, Reichard U, Goosmann C, Fauler B, Uhlemann Y, Weiss DS, Weinrauch Y, Zychlinsky A: Neutrophil extracellular traps kill bacteria. Science 2004;303:15321535.

15 Braian C, Hogea V, Stendahl O: Mycobacterium tuberculosis-induced neutrophil extracellular traps activate human macrophages. J Innate Immun 2013;5:591-602.

16 Christenson K, Björkman L, Karlsson A, Bylund J: Regulation of neutrophil apoptosis differs after in vivo transmigration to skin chambers and synovial fluid: a role for inflammasome-dependent interleukin- $1 \beta$ release. J Innate Immun 2013;5:377-388.

17 Dwyer M, Shan Q, D'Ortona S, Maurer R, Mitchell R, Olesen H, Thiel S, Huebner J, Gadjeva M: Cystic fibrosis sputum DNA has NETosis characteristics and neutrophil extracellular trap release is regulated by macrophage migration-inhibitory factor. J Innate Immun 2014;6:765-779.

18 Strydom N, Rankin SM: Regulation of circulating neutrophil numbers under homeostasis and in disease. J Innate Immun 2013;5:304314 